\title{
EL VOCABLO ÁRABE «SIKKA» EN SU ACEPCIÓN DE VÍA $Y$ SUS POSIBLES ARABISMOS EN LA TOPONIMIA HISPÁNICA: ACECA, SECA Y VILLA SECA
}

\author{
Por \\ M. ${ }^{\circledR}$ JESÚS RUBIERA MATA
}

El vocablo árabé sikka tiene una interesante evolución semántica. Su sentido originario parece ser el de «instrumento de hierro" por lo que sirvió para designar diversos utensilios de este metal con interesantes derivados por metonimia:

Reja del arado y, por metonimia, la extensión de terreno que puede labrar un solo arado (1), lo mismo que el español vugada.

Punzón para grabar las monedas y, de nuevo por metonimia, moneda. Como es bien conocido, de Dâr as-Sikka "casa de la moneda" procede el arabismo español ceca y cequí "cierta moneda" (2).

Garfio, Ancla. Ambas acepciones parecen ser del árabe andalusí, porque están registradas por Pedro de Alcalá (3).

Vía, camino. Aparentemente este significado no parece tener relación con un instrumento de hierro, pero creemos que puede haber nacido a partir de las huellas dejadas por las llantas metálicas de los carruajes -el hierro se usó para este fin desde la antigüedad - y esta evolución es semejante al castellano vía, una de cuyas acepciones es uespacio que hay entre los carriles que señalan las ruedas de los carruajes", según el Diccionario de la Real Academia. En este sentido el arabe sikka y el castellano via, han pasado a designar las vias del tren: sikka hadidiyya.

El origen de esta acepción de sikka como espacio entre dos carriles parece reflejarse en el significado matizado de la clase de camino que designa: un camino limitado por líneas de palmeras, como en Yãqüt (4), o por casas en su significado de calle, o el que registra Dozy (5) de tajo, espacio vacio abierto a través de un bosque.

(1) R. Dozy, Supplement aux Dictionnaires arabes. Beirut, 1981 ir 18811, 1, 666.

(2) J. CorominasiJ. A. Pascual. Diccionario etimológico castellano e hispánico, Madrid, 1980, 1 s.v

(3) Dozy ibidem.

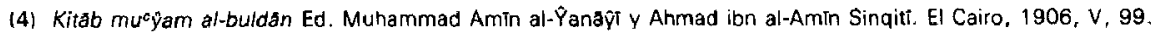

(5) Dozy, ibidem. 
A partir de vía, sikka toma también la acepción de estación o lugar donde se para en un viaje, sentido que Dozy registra en al-Bakri (6) y que también se encuentra en al-UUdrī (7) (Itinerario de Sevilla a Cordoba), es decir que era un sentido usado en alAndalus. Esta acepción de "estación o parada en el camino" nos interesa especialmente porque es la que ha producido seguramente los toponimos andalusies as-sikka como nombre propio y probablemente con el sentido de lugar de jornada en el camino o estación: Bališ (Vélez Rubio), conocida por as-Sikka en lbn al-Abbār (8), lugar aún hoy en día importante como etapa entre Murcia y Granada; as-Sikka en los documento,s mozárabes de Toledo (9) que corresponde al actual Aceca, situada en un vado del rio Tajo, y as-Sikka o Sikkat "Umar, a una jornada de Alcalá, lugar de etapa de Alfonso I el Batallador en su campaña "mozárabe» y que J. Vallvé identifica con la actual Acequia Alta (10)

En castellano la evolución normal de Sikka/ as-Sikka es ceca/ Aceca como demuestran los arabismos ya mencionados. Sin embargo es posible encontrar toponimos Seca que corresponden a este étimo y que se encuentran en zona lingüística del catalán, del euskera o del dialecto andaluz, es decir en zonas de seseo del castellano. C. Barceló (11) de la etimología de Sikka a dos topónimos Seca situados en Sagunto y Burriana. J. Vallvé considera que as-Sikka que aparece en al-Qartāyannî, puede corresponder al Rincón de Seca en Murcia (12), lo que es coherente con el seseo murciano de algunos topónimos bajo la influencia de los conquistadores catalanes.

Si algunos Seca de la toponimia hispánica pueden corresponder al étimo Sikka árabe y no al sicca latino, apuntamos la posibilidad que algunas Villa Seca o Vila Seca de nuestra geografía puedan atender a esta etimología, dado en primer lugar que no es extraño encontrar toponimos híbridos formados por el Villa Vila románico y un nombre árabe (13), y en segundo, que estos lugares se encuentren en importantes caminos históricos.

En zona de lengua catalana podrian corresponder a esta etimologia híbrida:

Vila Seca de Solcina (Tarragona) población por cuyo término pasaba la Vía Augusta $y$ en donde se encontró un miliário (14).

Torre de Vila Seca en Tortosa (Tarragona). Se trata de una torre, hoy desaparecida, que se encontraba en la orilla derecha del Ebro frente a Tortosa (15), cerca del lugar por donde la Vía Augusta cruzaba el Ebro por puente de barcas.

Vila Seca de Villareal (Castellón). Se trata de un despoblado en donde se ha hallado cerámica musulmana (16), situado en la confluencia de la Rambla de la Viuda y el río Mijares. Algunos autores consideran que por este punto pasaba la Vía Augusta (17), y de lo que no hay duda es que por alli pasaba un camino medieval que ha dejado

(6) Dozy ibidem.

(7) Tarst̃ al-Ajbār. Ed. Al-Ahwani, Madrid, 1965 pp. 109-110.

18. Takmila. B.H.A.

19l M. Asín. Contribucion a la toponimia árabe de España. Madrid-Granada, 1944 p. 42.

(10) “La cora de Jaén.» Al-Andalus XXXIV, 1969, I, p. 60

(11) Toponimia arabica del País Valencià. Xàtiva, 1982 p. 274.

(12) "La cora de Tudmir (Murcia)." Al-Andalus XXXVIi, 1972, 1 p. 175.

(13) M. Asin op. cit. supra. p. 139-142.

(14) F. Palli Aguilera. La Via Augusta en Cataluña. Barcelona, 1985, p. 111

(15) R. MiravallfJ. Alavedra. Les torres de la regío martima de L'Ebre, Tortosa, 1980, p. 44.

(16) P. Guichard/N. Mesado. Un menut poble del Pais Valencià: durant l'època musuimana: Borriana, Burriana, 1976.

(17) A. Chabret Fraga, Vias romanas de la provincia de Castellón Valencia, 1978, p. 44. J. G. Morote "El trazado de la VIa Augusta desde Tarracone a Carthagine Spartarian, Saguntum, 1979, pp. 139-164. 
los restos de un puente y una ermita (Santa Quiteria) que era un antiguo albergue medieval.

Fuera del dominio del catalán hemos encontrado una Villa Seca - junto a un Castil Seco-que creemos que pueden corresponder a la misma etimología. En primer lugar porque se encuentran en La Rioja, al pie de los Montes Oberenes, en una zona donde abundan los topónimos vascuences como Sajazarra, Galbáruli, lo que indicaría la presencia histórica del euskera en la época de la repoblación cristiana y como consecuencia un posible seseo. En segundo lugar porque también en la misma zona se encuentran algunos topónimos híbridos de étimo árabe y romance y cuyo ejemplo más significativo es Villavenazar (Villa de lbn Nasr), mencionada en el término de Grañon, al sur de Villa Seca.

Al interés lingüistico de esta zona donde se encuentran topónimos vascuences, castellanos y árabes, se une el histórico. Villa Seca y Castil Seco se encuentran an el camino que conduce al desfiladero de Foncea o de la Hoz de la Morcuera, el paso de los Montes Obarenes con el vecino Pancorbo hacia la llanada de Álava. Este paso de la Hoz de la Morcuera, al estar situado más al este que Pancorbo, es la entrada más lógica para el caminante que se dirigiera desde el Ebro a Alava. Este tema ya lo hemos tratado en otro lugar (18), pero resumiremos aquí nuestra hipótesis: los ejércitos musulmanes que durante el siglo IX lanzaron diversas campañas contra Álava, siempre que proviniesen de Zaragoza, utilizarían el desfiladero de Foncea u Hoz de la Morcuera (19), en lugar de Pancorbo. Y en este desfiladero habría que situar los problemáticos topónimos que aparecen en las crónicas árabes que describen estas campañas como la del año 801 «en un desfiladero de la cordillera cantábrica difícil de localizar" (20); la del río Oron en el año 816 (21) y la del falso Guernica del año 823 (22). Esta hipótesis podría ser confirmada si alguna vez se recupera para su estudio el perdido Muqtabis de Ibn Hayyãn que utilizó Lévi-Provençal.

A la entrada del desfiladero de la Hoz de la Morcuera o Foncea se encuentra el castillo de Cellórigo que se menciona en la Crónica de Albelda (23) y el pueblo más cercano en dirección hacia Haro es Vila Seca, quedando entre ambos Castilseco, sobre la ladera de un monte, como si vigilase el camino entre los dos lugares, función que creemos que realizaba. La existencia de este camino parece atestiguada en época medieval: en el fuero de Miranda de Ebro de finales del siglo XI aparece Villa Seca y aparece relacionada con un camino que pasaba por ella y atravesaba el campo de Sajazarra (24), lo que nos puede indicar la dirección del camino hacia Haro.

En el mismo Fuero aparece Castil Seco (Castrum Sicum) al cual se llega por un sendero que sale de la vía que atraviesa por Sajazarra y que según este texto se dirige a Granon situada en el Camino de Santiago, cerca de Santo Domingo de la Calzada $(25)$.

\footnotetext{
118) M. J. Rubiera de Epalza. "Alava y los alaveses en los textos árabes medievalesn en "La formación de Alava. Congreso de Estudios Historicos". Alava-Gasteiz, 1984, pp. 385-393.

\{19\} Apuntamos aqui que tal vez el toponimo Fonzaleche situado junto a Foncea (Pueblo, Montaña y destiladero) pudiera ser un híbrido de Foncea - nombre de etimologia para nosotros desconocida - y al-Fầy, desfiladero.

(20) E. Lévi-Provençal. Historia de España R. Menéndez Pidal España Musuimana, Madrid, 1957, IV, p. 113.

(21) Lévi-Provençal, op. cit. supra, p. 114

(22) Lévi-Provençal, op. cit. supra, p. 136

(23) Ed. Gómez Moreno. Madrid, 1932, p. 606.

1241 Angel Casimiro de Govantes. Diccionario Geográfico-Histórico de España. La Rioja. Madrid, 1846. pp. 214-215.

(25) Govantes, op. cit. supra, p. 52.
} 
La existencia de este camino medieval, al menos a finales del XI, que pasaba por Villa Seca, nos inelina a pensar que pudiese existir en época árabe como Sikka, nombre que perduró, pero, al no tener significado para los cristianos, se confundió con su homofono sicca y que por tanto Villa Seca de la Rioja y su castillo Castil Seco podrian corresponder al étimo árabe. 